\title{
Self-Efficacy Affects Cancer Patients in Solving Problems, Seeking Support and Avoiding Problems as Coping Mechanisms
}

\author{
Yesiana Dwi Wahyu Werdani ${ }^{1}$, Pascalis Arief Ardiansyah Silab ${ }^{2}$ \\ ${ }^{1,2}$ Faculty of Nursing Widya Mandala Catholic University Surabaya, Indonesia \\ Corresponding Author: Yesiana Dwi Wahyu Werdani (ywerdani@yahoo.com)
}

\begin{abstract}
Background: Cancer is a disease that causes various physical and mental problems. Being diagnosed with cancer affects the self-efficacy and behavior of individuals to choose a coping mechanism in facing the problem.

Purpose: This study aimed to determine the effect of self-efficacy on solving problems, seeking support, and avoiding problems as coping mechanisms in cancer patients.

Methods: A cross-sectional study was conducted on 45 cancer patients selected using a total sampling technique from two public health centers in Surabaya, Indonesia. Data were collected using the General Self-Efficacy Scale and Coping Strategy Indicator, and analyzed using the Shapiro Wilk for data normality, and linear regression to determine the effects of self-efficacy on solving problems, seeking support, and avoiding problems with $\mathrm{p}<0.05$.

Results: The results showed the participants' rate of self-efficacy levels $(M=3.26)$, and coping mechanism levels in solving problems $(M=3.46)$, seeking support $(M=2.88)$, and avoiding problems $(M=3.27)$, as well as mean scores of self-efficacy $(32.6 \pm 3.8)$, solving

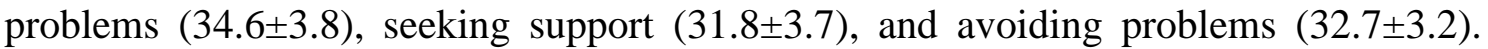
Based on the linear regression test, there was a significant effect self-efficacy on solving problems $\left(\mathrm{p}<0.001 ; \mathrm{R}^{2}=0.97\right)$, seeking support $\left(\mathrm{p}<0.001 ; \mathrm{R}^{2}=0.98\right)$, and avoiding problems $\left(\mathrm{p}<0.001 ; \mathrm{R}^{2}=0.98\right)$ as coping mechanisms.

Conclusion: Cancer patients who had high self-efficacy scores would choose solving problems and seeking support as the coping mechanisms, but those with lower scores on self-efficacy prefer to avoid the problems.
\end{abstract}

Keywords: Avoiding problems; seeking support; self-efficacy; solving problems

How to cite: Werdani, Y. D. W., \& Silab, P. A. A. (2020). Self-efficacy affects cancer patients in solving problems, seeking support, and avoiding problems as coping mechanisms. Nurse Media Journal of Nursing, 10(2), 146-157. doi:10.14710/nmjn.v10i2.26803

Permalink/DOI: https://doi.org/10.14710/nmjn.v10i2.26803

\section{BACKGROUND}

Cancer is known as a deadly and incurable disease. Globally, cancer is estimated to increase to 18.1 million new cases, and in 2018 there are an estimated 9.6 million deaths 
from cancer. Cancer deaths worldwide in 2018 is estimated to occur in Asia, partly because this region has almost $60 \%$ of the global population. In Europe, there are $20.3 \%$ and $14.4 \%$ in America. The proportion of cancer deaths in Asia and Africa $(57.3 \%$ and $7.3 \%$, respectively) is higher than the proportion of incident cases $(48.4 \%$ and $5.8 \%$, respectively) as these areas have a higher frequency (World Health Organisation, 2018). The prevalence of cancer in Indonesia is 1.8 per thousand inhabitants. The highest prevalence is in Yogyakarta province, while the lowest one is in West Nusa Tenggara. The highest prevalence of cancer is in the age group of 55-64 years old, at 4.6 per thousand inhabitants, while the lowest one is in children aged $<1$-year-old. Based on sex, women tend to have a higher risk than men (Health Research and Development Agency, 2018).

Fear, trauma, or feeling close to death are the first responses when diagnosed with cancer (Robb, Simon, Miles, \& Wardle, 2014). The majority of cancer patients feel anxious and worried about an uncertain future (Grupe \& Nitschke, 2013), and also feel severe stress (Werdani, 2017). The high emotional stress affects the patients' functional status and causes the patients to lose enthusiasm for life (Saeedi-Saedi, Shahidsales, Koochak-Pour, Sabahi, \& Moridi, 2015). Cancer patients who experience anxiety and depression greatly influence their self-efficacy (Omran \& Mcmillan, 2018), and are more likely to have low self-efficacy scores (Rizeanu, Bubulac, \& Popa-velea, 2018). Self-efficacy has an influence on physical and mental health, quality of life, and health information-seeking behaviour in cancer patients (BorjAlilu, Kaviani, Helmi, Karbakhsh, \& Mazaheri, 2017). A study stated that self-efficacy is considered a form of coping that can affect the quality of life in cancer patients (Chirico et al., 2017). Coping strategies that focus on emotions have a significant negative correlation with total symptoms and functional dimensions in the quality of life (Kahrazei \& Maleknia, 2015).

Cancer management through therapy in patients has various side effects, such as pain, nausea, vomiting, fatigue, hair loss, excessive bleeding, weight loss, fever, diarrhea, and lumps (Aslam et al., 2014), as well as sleeplessness, difficulty in breathing, anorexia, and constipation (Afiyanti, Wardani, \& Martha, 2019). These physical effects can cause changes in the psychological conditions of cancer patients, such as depression and stress. A study reported that cancer patients who experienced cancer-related fatigue (CRF) feel stress, depression, and anxiety; furthermore, the stress is closely related to worse rates of survival and higher mortality in cancer patients (Weber \& O'Brien, 2017). The individuals' responses to stress are shown to be coping mechanisms. A study stated that cancer patients who experienced mild to moderate stress tend to have adaptive coping mechanisms, while those who experienced severe stress tend to prefer maladaptive coping mechanisms (Werdani, 2017). Coping strategies commonly used by cancer patients were seeking emotional support, positive reframing, self-blame, and denial, which affects the quality of life (Nipp et al., 2016). A majority of previous studies examined psychological disorders such as stress, anxiety, and depression, which can affect self-efficacy, and coping strategies related to the quality of life, as well as the relationship between self-efficacy and general coping mechanisms (adaptive or maladaptive copings). However, no research studied the effects of self-efficacy on three dimensions of coping mechanism details (solving problems, seeking support avoiding problems), especially in cancer patients. It is, therefore, necessary to examine how self- 
efficacy affects solving problems, seeking support, and avoiding problems as coping mechanisms in cancer patients.

\section{PURPOSE}

This study aimed to determine the effects of self-efficacy on solving problems, seeking support, and avoiding problems as coping mechanisms in cancer patients.

\section{METHODS}

\section{Design and samples}

The present research was a cross-sectional study, involving simultaneous data collection on independent and dependent variables. The samples were 45 cancer patients were conscious and aged more than 17 years old in two public health centers in Surabaya, Indonesia. A total sampling technique was used to recruit the samples.

\section{Instruments and data collection}

This study used the General Self-Efficacy Scale (GSE) adopted from a previous study by De las Cuevas and Peñate (2015) to measure self-efficacy's scores, and the Coping Strategy Indicator (CSI) adopted from Togas and Alexias (2018) to measure the scores of solving problems, seeking support, and avoiding problems. The GSE consists of 10 closed-ended questions using a 4-point Likert scale $(1=$ not at all true, $2=$ hardly true, $3=$ moderately true, $4=$ exactly true). Meanwhile, the CSI is composed of three parts. The first part consists of 11 closed-ended questions that describe solving problems, while the second and third part consists of 10 closed-ended questions each that describe seeking support and avoiding problems, respectively. The section of solving problems and seeking support uses a 4-point Likert scale (1=never, 2=occasionally, 3=sometimes, $4=$ always), while the section of avoiding problems applies reversed Likert scales ( 1 =always, $2=$ sometimes, $3=$ occasionally, $4=$ never). The questionnaires had been backto-back translated into the Indonesian version by reliable translators, and tested for their validity and reliability by the researchers. The general self-efficacy scale showed the $\mathrm{R}$ of 0.831-0.948 with a Cronbach's alpha of 0.921, while the coping strategy indicator showed the R of 0.890-0.932, with a Cronbach's alpha of 0.931. After consented for participation, respondents completed the demographic data and the questionnaires. The data were collected in April 2019.

\section{Data analysis}

The collected data were entered into SPSS 25.0 and tested for normality using the Shapiro Wilk test $(\mathrm{p}>0.05)$. The results showed that the data were normally distributed ( $p=0.314$ for self-efficacy; $p=0.60$ for solving problems; $p=0.195$ for seeking support, and $p=0.165$ for avoiding problems). A further analysis was performed using the step linear regression test to examine effects of self-efficacy on solving problems, seeking support, and avoiding problems.

\section{Ethical considerations}

This study obtained ethical approval from the Research Ethics Committee of Medical Faculty, Widya Mandala Catholic University (No. 003/WM12/KEPK/T/2019). Prior to the study, all respondents were informed of the research purposes, advantages, procedures, and risks, as well as signed an informed consent. 


\section{RESULTS}

\section{Characteristics of participants}

The result showed that more than half of the participants were old, ranging from early older adults to the elderly. The stages of cancer varied from stage I-IV, and most of the participants have been diagnosed with cancer for 1-3 years. Almost all participants had a support system from their nuclear families, such as their parents, daughter, or son.

Table 1. Demographic characteristics of the respondents $(n=45)$

\begin{tabular}{lrr}
\hline \multicolumn{1}{c}{ Variables } & $n$ & $\%$ \\
\hline Age (years), M \pm SD = 54.1 \pm 13.8 & & \\
$17-25$ (adolescent) & 3 & 7 \\
$26-35$ (early adulthood) & 1 & 2 \\
$36-45$ (late adulthood) & 7 & 16 \\
$46-55$ (early older adult) & 11 & 24 \\
$56-65$ (late older adult) & 14 & 31 \\
$>65$ (elderly) & 9 & 20 \\
Gender & & \\
Female & 34 & 76 \\
Male & 11 & 24 \\
Cancer Stage & & \\
I & 1 & 2 \\
II & 20 & 44 \\
III & 16 & 36 \\
IV & 7 & 16 \\
Unknown & 1 & 2 \\
Duration of cancer diagnosed (year) & & \\
<1 & 3 & 7 \\
1 - 3 & 23 & 51 \\
4-6 & 8 & 18 \\
$\quad$ 6 & 11 & 24 \\
Support system & & \\
Nuclear families & 38 & 85 \\
Extended families & 5 & 11 \\
Others & 1 & 2 \\
Alone & 1 & 2 \\
\hline
\end{tabular}

\section{Self-efficacy in cancer patients}

Table 2 showed that in the level of self-efficacy in cancer patients, there were three top components of self-efficacy, comprised of managing to solve the difficult problems $(M=3.47)$, ability to adapt to all situations $(M=3.38)$, and finding a way out of the problems $(M=3.33)$.

Table 2. Self-efficacy in cancer patients $(n=45)$

\begin{tabular}{llcccc}
\hline & \multicolumn{1}{c}{ Component of Self-Efficacy } & Min & Max & Mean & SD \\
\hline 1. & I always manage to solve difficult problems & 3 & 4 & 3.47 & 0.50 \\
2. & I can find a way out of problems & 2 & 4 & 3.33 & 0.52 \\
3. & I have no difficulty in achieving a goal & 2 & 4 & 3.02 & 0.58 \\
\hline
\end{tabular}




\begin{tabular}{llcccc}
\hline \multicolumn{1}{c}{ Component of Self-Efficacy } & Min & Max & Mean & SD \\
\hline 4. & I can adapt to all situations & 2 & 4 & 3.38 & 0.58 \\
5. I can solve problems in any situation and condition & 2 & 4 & 3.31 & 0.56 \\
6. I have a solution for every problem & 2 & 4 & 3.24 & 0.57 \\
7. & I'm sure that I can solve a problem with the ability that I & 2 & 4 & 3.29 & 0.59 \\
$\quad$ have & & & & \\
8. I have been able to overcome every difficulty because I & 2 & 4 & 3.16 & 0.47 \\
$\quad$ had many ideas & 2 & 4 & 3.16 & 0.47 \\
9. If I am in trouble, I can think of a solution quickly & 2 & 4 & 3.27 & 0.54 \\
10. I am always ready to face problems & & &
\end{tabular}

\section{Dimensions of coping mechanisms in cancer patients}

Table 3 showed that there were three top components in solving problems $(M=3.46)$, comprising of enthusiasm and effort in solving the problems $(\mathrm{M}=3.84)$, full attention to solve the problem $(M=3.80)$, and planning an action carefully before doing something $(M=3.60)$. For seeking support as a coping mechanism $(M=2.88)$, there were two top components, comprising of the hope that the family will continue to help in solving a problem $(M=3.49)$, and receiving help and support from friends and family in solving the problem $(M=3.29)$. For avoiding problems as a coping mechanism $(M=3.27)$, there were three top components in avoiding problems, comprising of staying away from others $(M=3.73)$, avoiding others $(M=3.64)$, and relieving stress by imagination $(M=3.64)$.

Table 3. Dimensions of coping mechanism in cancer patients $(n=45)$

\begin{tabular}{|c|c|c|c|c|}
\hline Coping Mechanisms & Min & $\operatorname{Max}$ & Mean & SD \\
\hline \multicolumn{5}{|l|}{ Solving problems } \\
\hline $\begin{array}{l}\text { 1. When I get into trouble, I think of a way out of my } \\
\text { problem }\end{array}$ & 1 & 4 & 3.33 & 0.74 \\
\hline 2. I think first before making a decision & 2 & 4 & 3.56 & 0.66 \\
\hline I have several ways to deal with difficult situations & 1 & 4 & 3.00 & 0.80 \\
\hline 4. In making choices, I'm always careful & 2 & 4 & 3.49 & 0.73 \\
\hline I thought of a solution to the problem I was having & 1 & 4 & 3.36 & 0.83 \\
\hline I turned my full attention to solving a problem & 3 & 4 & 3.80 & 0.40 \\
\hline I have a plan for every problem I faced & 1 & 4 & 3.13 & 0.99 \\
\hline $\begin{array}{l}\text { 8. I remained enthusiastic and made an effort to solve the } \\
\text { problems I faced }\end{array}$ & 2 & 4 & 3.84 & 0.42 \\
\hline 9. I tried to solve the problem I was facing & 2 & 4 & 3.56 & 0.72 \\
\hline 10. I plan an action carefully before doing something & 1 & 4 & 3.60 & 0.75 \\
\hline \multicolumn{5}{|l|}{ Seeking support } \\
\hline 1. I tell friends about my problems & 1 & 4 & 2.58 & 0.69 \\
\hline $\begin{array}{l}\text { 2. Even though I am in trouble, I still get the attention and } \\
\text { support of others and my family }\end{array}$ & 2 & 4 & 3.71 & 0.59 \\
\hline $\begin{array}{l}\text { 3. I feel better if I share the problem I am facing with } \\
\text { others }\end{array}$ & 1 & 4 & 2.80 & 0.87 \\
\hline $\begin{array}{l}\text { 4. I talk to my family about the fears and worries that I am } \\
\text { experiencing now }\end{array}$ & 1 & 4 & 2.64 & 0.98 \\
\hline $\begin{array}{l}\text { 5. Telling others about my situation can help me find a } \\
\text { solution }\end{array}$ & 1 & 4 & 2.80 & 0.81 \\
\hline
\end{tabular}




\begin{tabular}{|c|c|c|c|c|}
\hline Coping Mechanisms & Min & Max & Mean & SD \\
\hline \multirow{2}{*}{$\begin{array}{l}\text { 6. I went to a health professional to help me feel better } \\
\text { 7. I went to a friend to help me feel better about the } \\
\text { problem }\end{array}$} & 1 & 4 & 2.56 & 0.87 \\
\hline & 1 & 4 & 2.22 & 0.97 \\
\hline $\begin{array}{l}\text { 8. My friends always provide solutions when I am in } \\
\text { trouble }\end{array}$ & 1 & 4 & 2.82 & 0.96 \\
\hline $\begin{array}{l}\text { 9. I get sympathy and attention from people who have the } \\
\text { same problem as me }\end{array}$ & 1 & 4 & 2.84 & 0.98 \\
\hline $\begin{array}{l}\text { 10. I received help and support from friends and family in } \\
\text { solving the problem I was experiencing }\end{array}$ & 1 & 4 & 3.29 & 0.89 \\
\hline $\begin{array}{l}\text { 11. I hope my family will continue to help me in solving my } \\
\text { problem }\end{array}$ & 1 & 4 & 3.49 & 0.84 \\
\hline \multicolumn{5}{|l|}{ Avoiding problems } \\
\hline 1. I hid the problem I was experiencing & 1 & 5 & 3.18 & 1.05 \\
\hline 2. I relieve stress by imagining & 1 & 4 & 3.64 & 0.68 \\
\hline 3. I spent more time alone & 1 & 4 & 3.40 & 0.84 \\
\hline 4. I watched television more than usual & 1 & 4 & 2.58 & 1.03 \\
\hline 5. I avoid others because of the problems I faced & 1 & 4 & 3.64 & 0.65 \\
\hline 6. I avoid problems by doing activities that I like & 1 & 4 & 2.44 & 1.27 \\
\hline 7. I relieve stress with lots of sleep & 1 & 4 & 3.09 & 1.00 \\
\hline 8. I feel that the problem I experienced is not real & 1 & 4 & 3.42 & 0.92 \\
\hline $\begin{array}{l}\text { 9. I feel that the problem I experienced is the same as a } \\
\text { story in a movie or novel }\end{array}$ & 1 & 4 & 3.60 & 0.69 \\
\hline 10. I want others to stay away from me & 1 & 4 & 3.73 & 0.72 \\
\hline
\end{tabular}

Effects of self-efficacy on solving problems, seeking support and avoiding problems Table 4 showed that the mean score of all variables was high, meaning that most participants had high self-efficacy and positive problem-solving and positive support seeking, and less problem avoidance as a coping mechanism. While based on the linear regression, it is shown that there was a significant effect of self-efficacy on these three forms of coping mechanisms. Self-efficacy had an effect of $97.7 \%$ on solving problems, $98.3 \%$ on seeking support and $98.4 \%$ on avoiding problems.

Table 4. Effects of self-efficacy on solving problems, seeking support and avoiding problems $(n=45)$

\begin{tabular}{lcccccccc}
\hline \multicolumn{1}{c}{ Variable } & \multicolumn{4}{c}{ Descriptive Statistics } & \multicolumn{4}{c}{ Self-Efficacy } \\
\cline { 2 - 9 } & Min & Max & Mean & SD & $R$ & $R^{2}$ & $\beta$ & $p$-value \\
\hline Solving problem & 25.00 & 40.00 & 34.6 & 3.8 & 0.988 & 0.977 & 0.937 & $<0.001$ \\
Seeking support & 22.00 & 43.00 & 31.8 & 3.7 & 0.992 & 0.983 & 1.251 & $<0.001$ \\
Avoiding problem & 26.00 & 38.00 & 32.7 & 3.2 & 0.992 & 0.984 & 0.721 & $<0.001$ \\
\hline
\end{tabular}

\section{DISCUSSION}

The present study aimed to determine the effects of self-efficacy on solving problems, seeking support, and avoiding problems as coping mechanisms in cancer patients. Results showed that cancer patients had a high score of self-efficacy, in which they managed and found a way out to solve difficult problems and could adapt to situations. Self-efficacy helps overcome the problems that vary greatly from the consequences of cancer and the effects of treatment (Foster et al., 2015). A similar result also reported 
that 112 patients undergoing adjuvant endocrine therapy showed that those with higher self-efficacy were able to overcome physical symptoms of cancer and had a significant relationship related to greater functional, emotional, and social well-being (Shelby et al., 2014). Another study stated there was a positive relationship between self-efficacy and quality of life, the ability to adapt to cancer diagnosis, and reduce the distress of cancer patients (Wang, Liu, Shi, \& Wang, 2016). Someone with self-efficacy is more likely to be adaptable and has a high desire to live. The adaptation process of adult cancer patients starts from facing an unknown situation, followed by patients looking for relevant information and decision-making considerations, and also listening to healthcare professionals' suggestions so that the patients get a chance to extend their life and the desire to survive (Chao, Wang, Hsu, \& Wang, 2015). Patients who have good self-efficacy will achieve a good quality of life. This was also reported by a study of 100 breast cancer patients that there was a significant relationship between self-efficacy and the quality of life of patients, including physical health, mental health, social relationships and satisfaction with the environment (Moradi et al., 2017).

Another finding of this study showed a significant effect of self-efficacy on solving problems, which means that the participants who are eager to choose solving problems as a coping mechanism to respond to the stressors have an adaptive coping mechanism. This has been seen from the component of solving problems, that the participants were enthusiastic, full of attention, and could plan their actions to solve a problem. This result is supported by another study where patients who have high expectations resulted in the improvement of self-confidence, self-efficacy, and high welfare, and caused patients to have strong support for using strategies to achieve their goals in solving problems (Bahryni, Bermas, \& Tashvighi, 2016). A similar result declared that among 121 breast cancer patients undergoing surgery, those who had less emotional distress also had more positive problem-solving (Heppner, Armer, \& Mallinckrodt, 2009). Based on the findings of this study, the majority of participants were in the old age (54.1 years), had cancer stage of II and III, and had also been diagnosed with cancer for more than 1 year. All of these participants chose to solve problems with adaptive and positive coping mechanisms. This result is supported by another study where 281 participants with gynecologic cancer having the mean age of 54.8 and in stage II and III of cancer predominantly also had resilience in psychologically adapting, and expressed three types of coping strategies, namely positive emotions, reframing cancer experiences positively, and fostering a sense of peace and meaning in life. This causes a good quality of life (Manne et al., 2015). Another research stated that positive coping was found in women cancer patients undergoing cancer treatment and were diagnosed for cancer for more than 6 months (Kvillemo \& Bränström, 2014).

Our findings also showed that self-efficacy affected seeking support. The participants hoped for and received help and support from friends and family in solving the problem. Seeking support is an effort made to seek help from those who are relevant to others to help to solve problems (Zartaloudi \& Madianos, 2010). A study reported that patients who had problems were more likely to seek support from parents, friends, partners (Chow \& Glaman, 2013). A study conducted for individuals who were depressed and anxious found that $47 \%$ sought support from professional experts to help solve their problems (Wallerblad, Möller, \& Forsell, 2012). This study found that the majority of 
participants had been diagnosed with cancer for more than 1 year and the nuclear family lived with patients to provide support. A study stated that cancer patients who were diagnosed in the first 1-3 years experienced shock disorders such as physical, emotional, social, work, and financial stress, which made them in dire need of support from others (Stanton, 2012). Another study also explained that cancer survivors decided to seek support, especially from family members such as children, parents, siblings and more distant relatives to help them making treatment decisions, emotional support, inspiration, motivation, informational support, and spiritual support, and provide facilities (Muhamad, Afshari, \& Kazilan, 2011). A qualitative descriptive study of 14 breast cancer patients stated that family support could increase individual involvement in the fight against cancer (Chung \& Hwang, 2012). Seeking support, which is a finding of this research, is also caused by the active involvement of cancer survivors in community activities. The findings in this study are supported by the results of another study, which stated that the majority of cancer patients who were more than 50 years old and were active in online community groups had a better atmosphere and quality of life (van Eenbergen, van de Poll-Franse, Heine, \& Mols, 2017). The same results were also presented by a study which stated that the involvement of cancer patients in a support group in online communities could improve the ability to express emotions properly, and was beneficial for improving the health condition of patients (Han et al., 2011). A study explained that breast cancer patients had a high awareness to know more about the disease and its treatment, therefore, the majority of patients visited health professionals to consult their problems (Agbokey et al., 2019).

Participants in this study having low scores on self-efficacy are more likely to choose to avoid problems as an alternative coping mechanism. Avoiding as coping is a form of individual behavior that seeks to avoid, deny, ignore and not solve problems properly which causes the individual to be in a stressful situation (Holahan, Moos, Holahan, Brennan, \& Schutte, 2005). A study of 97 gynecological cancer stated that patients who lacked self-confidence and were pessimistic had a significant association with the onset of anxiety and depression (Zenger, Glaesmer, Hockel, \& Hinz, 2011). Older people who are diagnosed with cancer are more anxious. It is supported by a study reporting that for patients diagnosed with cancer in late adulthood, 20\% of them tend to report prolonged anxiety (Mitchell, Ferguson, Gill, Paul, \& Symonds, 2013). Prolonged anxiety can cause an individual to feel hopeless; the hopelessness is related to cancer-related concerns, such as feeling different from others and feelings of alienation. Together, this can affect a patient's subjective responses, such as helpless responses, difficulty in resolving problems and affective disorders, and also poor general well-being (Grassi et al., 2010). Breast cancer patients experiencing a recurrence in four months after diagnosis reported feeling hopeless, feeling alone, and are very vulnerable to depression (Brothers \& Andersen, 2009). Cancer patients experiencing anxiety and depression at moderate levels are more likely to have coping strategies to avoid problems (Karabulutlu, Bilici, Çayır, Tekin, \& Kantarc1, 2010). Avoiding problems is one of the maladaptive coping mechanisms. Cancer patients experiencing excessive stress will perform maladaptive coping mechanisms, and use of maladaptive coping will further increase their psychological pressure and reduce their quality of life (Ravindran, Shankar, \& Murthy, 2019). A study of 346 patients undergoing palliative care with complex physical symptoms found that they had major coping strategies that focused on 
emotions, such as cognitive avoidance and fatalism; this selection of coping was influenced by socio-demographic variables and disease (Pereira \& de Brito Santos, 2016). The similarity in results was also reported in study where 22 patients of breast cancer that received adjuvant therapy felt emotional encounters, isolationism, fatalism, feeling guilt and blaming others, and also avoided the problems, such as avoided threatening and unpleasant thoughts (Hajian, Mehrabi, Simbar, \& Houshyari, 2017).

This study has limitations. The participants in this study were cancer patients with all stages and types of cancer, and therefore, which might influence the patients' responses to their condition. This study was also conducted with small sample size. Despite the limitations, this study could describe the self-efficacy and coping mechanisms of cancer patients.

\section{CONCLUSION}

The results of the study showed that self-efficacy affects the coping mechanism, where individuals who have positive self-efficacy will choose to solve problems and seek support as their coping mechanisms, while individuals with negative self-efficacy tend to choose to avoid the problem. The findings of this study are important to provide positive support to patients to increase self-efficacy, to be able to choose adaptive coping. Based on the finding of this study, it is recommended to explore the internal and external motivation of cancer patients to choose coping mechanisms in future studies.

\section{ACKNOWLEDGEMENT}

The researchers would like to thank Widya Mandala Catholic University Surabaya, Indonesia for funding this study.

\section{CONFLICT OF INTEREST}

The authors declare no conflict of interest.

\section{REFERENCES}

Afiyanti, Y., Wardani, I. Y., \& Martha, E. (2019). The quality of life of women with cervical cancer in Indonesia: A cross-sectional study. Nurse Media Journal of Nursing, 9(2), 128-140. doi:10.14710/nmjn.v9i2.26014

Agbokey, F., Kudzawu, E., Dzodzomenyo, M., Ae-Ngibise, K. A., Owusu-Agyei, S., \& Asante, K. P. (2019). Knowledge and health seeking behaviour of breast cancer patients in Ghana. International Journal of Breast Cancer, 2019, Article ID 5239840. doi:10.1155/2019/5239840

Aslam, M. S., Naveed, S., Ahmed, A., Abbas, Z., Gull, I., \& Athar, M. A. (2014). Side effects of chemotherapy in cancer patients and evaluation of patients opinion about starvation based differential chemotherapy. Journal of Cancer Therapy, 5(5), 817-822. doi:10.4236/jct.2014.58089

Bahryni, S., Bermas, H., \& Tashvighi, M. (2016). The self-efficacy forecasting based on hope to life and resiliency in adolescents suffering from cancer. Biomedical and Pharmacology Journal, 9(3), 1147-1156. doi:10.13005/bpj/1062

BorjAlilu, S., Kaviani, A., Helmi, S., Karbakhsh, M., \& Mazaheri, M. A. (2017). Exploring the role of self-efficacy for coping with breast cancer: A systematic review. Archives of Breast Cancer, 2, 42-57. doi:10.19187/ABC.20174242-57 
Brothers, B. M., \& Andersen, B. L. (2009). Hopelessness as a predictor of depressive symptoms for breast cancer patients coping with recurrence. Psycho-Oncology, 18(3), 267-275. doi:10.1002/pon.1394

Chao, Y. H., Wang, S.-Y., Hsu, T. H., \& Wang, K. W. K. (2015). The desire to survive: The adaptation process of adult cancer patients undergoing radiotherapy. Japan Journal of Nursing Science, 12(1), 79-86. doi:10.1111/jjns.12050

Chirico, A., Serpentini, S., Merluzzi, T., Mallia, L., Bianco, P. D. E. L., Martino, R., ... \& Laurentiis, M. D. E. (2017). Self-efficacy for coping moderates the effects of distress on quality of life in palliative cancer care. International Journal of Cancer Research and Treatment, 37(4), 1609-1615. doi:10.21873/anticanres.11491

Chow, C. M., \& Glaman, R. (2013). Support-seeking and closeness across social relationships: Relationship-general and relationship-specific levels analysis. Interpersona: An International Journal on Personal Relationships, 7(1), 88-96. doi:10.5964/ijpr.v7i1.114

Chung, C., \& Hwang, E. (2012). Couples' experiences of breast cancer in Korea. Cancer Nursing, 35(3), 211-220. doi:10.1097/NCC.0b013e31822a60db

De las Cuevas, C., \& Peñate, W. (2015). Validation of the General Self-Efficacy Scale in psychiatric outpatient care. Psicothema, 27(4), 410-415. doi:10.7334/psicothema2015.56.

Foster, C., Breckons, M., Cotterell, P., Barbosa, D., Calman, L., Corner, J., ... \& Smith, P. W. (2015). Cancer survivors' self-efficacy to self-manage in the year following primary treatment. Journal of Cancer Survivorship: Research and Practice, 9(1), 11-19. doi:10.1007/s11764-014-0384-0

Grassi, L., Travado, L., Gil, F., Sabato, S., Rossi, E., Tomamichel, M., ... \& Group, t. S. (2010). Hopelessness and related variables among cancer patients in the Southern European Psycho-Oncology Study (SEPOS). Psychosomatics, 51(3), 201-207. doi:10.1176/appi.psy.51.3.201

Grupe, D. W., \& Nitschke, J. B. (2013). Uncertainty and anticipation in anxiety: An integrated neurobiological and psychological perspective. Nature Reviews. Neuroscience, 14(7), 488-501. doi:10.1038/nrn3524

Hajian, S., Mehrabi, E., Simbar, M., \& Houshyari, M. (2017). Coping strategies and experiences in women with a primary breast cancer diagnosis. Asian Pacific Journal of Cancer Prevention: APJCP, 18(1), 215-224. doi:10.22034/APJCP.2017.18.1.215

Han, J. Y., Shah, D. V., Kim, E., Namkoong, K., Lee, S.-Y., Moon, T. J., ... \& Gustafson, D. H. (2011). Empathic exchanges in online cancer support groups: Distinguishing message expression and reception effects. Health Communication, 26(2), 185-197. doi:10.1080/10410236.2010.544283

Health Research and Development Agency. (2018). Hasil Utama Riskesdas 2018 [The main outcome of basic health research 2018]. Retrieved from https://www.litbang.kemkes.go.id/hasil-utama-riskesdas-2018/

Heppner, P. P., Armer, J. M., \& Mallinckrodt, B. (2009). Problem-solving style and adaptation in breast cancer survivors: A prospective analysis. Journal of Cancer Survivorship: Research and Practice, 3(2), 128-136. doi:10.1007/s11764-0090085-2 
Holahan, C. J., Moos, R. H., Holahan, C. K., Brennan, P. L., \& Schutte, K. K. (2005). Stress generation, avoidance coping, and depressive symptoms: A 10-year model. Journal of Consulting and Clinical Psychology, 73(4), 658-666. doi:10.1037/0022-006X.73.4.658

Kahrazei, F., \& Maleknia, N. (2015). The relationship between stress coping styles and quality of life among patients with breast cancer. Journal of Midwifery and Reproductive Health, 3(4), 472-478.

Karabulutlu, E. Y., Bilici, M., Çayır, K., Tekin, S. B., \& Kantarcı, R. (2010). Coping, anxiety and depression in Turkish patients with cancer. European Journal of General Medicine, 7(3), 296-302. doi:10.29333/ejgm/82872

Kvillemo, P., \& Bränström, R. (2014). Coping with breast cancer: A meta-analysis. PLoS ONE, 9(11), e112733. doi:10.1371/journal.pone.0112733

Manne, S. L., Myers-Virtue, S., Kashy, D., Ozga, M., Kissane, D., Heckman, C., ... \& Rosenblum, N. (2015). Resilience, positive coping, and quality of life among women newly diagnosed with gynecological cancers. Cancer Nursing, 38(5), 375382. doi:10.1097/NCC.0000000000000215

Mitchell, A. J., Ferguson, D. W., Gill, J., Paul, J., \& Symonds, P. (2013). Depression and anxiety in long-term cancer survivors compared with spouses and healthy controls: a systematic review and meta-analysis. The Lancet Oncology, 14(8), 721-732. doi:10.1016/S1470-2045(13)70244-4

Moradi, R., Roudi, M. A., Kiani, M. M., Mousavi Rigi, S. A., Mohammadi, M., Keshvari, M., \& Hosseini, M. (2017). Investigating the relationship between selfefficacy and quality of life in breast cancer patients receiving chemical therapy. Bali Medical Journal, 6(1), 6-11. doi:10.15562/bmj.v6i1.358

Muhamad, M., Afshari, M., \& Kazilan, F. (2011). Family support in cancer survivorship. Asian Pacific Journal of Cancer Prevention, 12(6), 1389-1397.

Nipp, R. D., El-Jawahri, A., Fishbein, J. N., Eusebio, J., Stagl, J. M., Gallagher, E. R., ... \& Temel, J. S. (2016). The relationship between coping strategies, quality of life, and mood in patients with incurable cancer. Cancer, 122(13), 2110-2116. doi:10.1002/cncr.30025

Omran, S., \& Mcmillan, S. (2018). Symptom severity, anxiety, depression, selfefficacy and quality of life in patients with cancer. Asian Pacific Journal of Cancer Prevention, 19(2), 365-374. doi:10.22034/APJCP.2018.19.2.365

Pereira, F. M. P, \& de Brito Santos, C. S. V. (2016). Psychological adaptation and its impact on the quality of life and spiritual well-being: A cross-sectional study of end of life cancer patients. Nursing and Palliative Care, 1(5). doi:10.15761/NPC.1000126

Ravindran, O. S., Shankar, A., \& Murthy, T. (2019). A comparative study on perceived stress, coping, quality of life, and hopelessness between cancer patients and survivors. Indian Journal of Palliative Care, 25(3), 414-420. doi:10.4103/IJPC.IJPC_1_19

Rizeanu, S., Bubulac, L., \& Popa-velea, O. (2018). Anxiety, perceived stress and selfefficacy of elderly oncology patients. American Research Journal of Geriatrics and Aging, 1(1), 1-7. doi:10.21694/2639-3093.18001

Robb, K. A., Simon, A. E., Miles, A., \& Wardle, J. (2014). Public perceptions of cancer: a qualitative study of the balance of positive and negative beliefs. $B M J$ Open, 4(7), e005434-e005434. doi:10.1136/bmjopen-2014-005434 
Saeedi-Saedi, H., Shahidsales, S., Koochak-Pour, M., Sabahi, E., \& Moridi, I. (2015). Evaluation of emotional distress in breast cancer patients. Iranian Journal of Cancer Prevention, 8(1), 36-41.

Shelby, R. A., Edmond, S. N., Wren, A. A., Keefe, F. J., Peppercorn, J. M., Marcom, P. K., .. \& K Kimmick, G. G. (2014). Self-efficacy for coping with symptoms moderates the relationship between physical symptoms and well-being in breast cancer survivors taking adjuvant endocrine therapy. Supportive Care in Cancer, 22(10), 2851-2859. doi:10.1007/s00520-014-2269-1

Stanton, A. L. (2012). What happens now? Psychosocial care for cancer survivors after medical treatment completion. Journal of Clinical Oncology, 30(11), 1215-1220. doi:10.1200/JCO.2011.39.7406

Togas, C., \& Alexias, G. (2018). Factor Structure and Psychometric Properties of the Greek Version of the Coping Strategy Indicator. International Journal of Caring Sciences, 11(1), 87-99.

van Eenbergen, M. C., van de Poll-Franse, L. V, Heine, P., \& Mols, F. (2017). The impact of participation in online cancer communities on patient reported outcomes: Systematic review. JMIR Cancer, 3(2), e15. doi:10.2196/cancer.7312

Wallerblad, A., Möller, J., \& Forsell, Y. (2012). Care-seeking pattern among persons with depression and anxiety: A population-based study in Sweden. International Journal of Family Medicine, 2012, 1-9. doi:10.1155/2012/895425

Wang, Z.-Y., Liu, L., Shi, M., \& Wang, L. (2016). Exploring correlations between positive psychological resources and symptoms of psychological distress among hematological cancer patients: A cross-sectional study. Psychology, Health \& Medicine, 21(5), 571-582. doi:10.1080/13548506.2015.1127396

Weber, D., \& O'Brien, K. (2017). Cancer and cancer-related fatigue and the interrelationships with depression, stress, and inflammation. Journal of EvidenceBased Complementary \& Alternative Medicine, 22(3), 502. doi:10.1177/2156587216676122

Werdani, Y. D. W. (2017). Effect of mindfullness meditation on stress level and coping mechanism in cancer patients. Folia Medica Indonesiana, 53(1), 33-40. doi:10.20473/fmi.v53i1.5488

World Health Organisation. (2018). Latest global cancer data: Cancer burden rises to 18.1 million new cases and 9.6 million cancer deaths in 2018. International Agency for Research on Cancer, 263(September), 13-15. Retrieved from http://gco.iarc.fr/

Zartaloudi, A., \& Madianos, M. (2010). Stigma related to help-seeking from a mental health professional. Health Science Journal, 4(2), 77-83.

Zenger, M., Glaesmer, H., Hockel, M., \& Hinz, A. (2011). Pessimism predicts anxiety, depression and quality of life in female cancer patients. Japanese Journal of Clinical Oncology, 41(1), 87-94. doi:10.1093/jjco/hyq168 